Recibido: 06-07-2016. Aceptado: 06.09.2016.

\title{
ANEXO III
}

"Convenios suscritos entre Estados Parte del Convenio Multilateral mediante los que se extiende la aplicación del mismo a regímenes y prestaciones no comprendidos en el ámbito de aplicación del Convenio Multilateral (artículo 3, apartado 5)”

\section{NICOLÁS ALEJANDRO OCCHI ORSARIA}

Docente Adscrito de Derecho del Trabajo y de la Seguridad Social

Universidad de Rosario (Argentina) 


\title{
RESUMEN
}

El Anexo III se halla totalmente vacío, dando como primera impresión que entre los Estados iberoamericanos el derecho internacional de la seguridad social no ha procurado más que acordar sobre prestaciones pecuniarias. Sin embargo, una mirada retrospectiva acompañada de reflexión detenida puede llegar a conjeturar la inexactitud de ese panorama, para después contemplar que esa carencia tendría una explicación práctica. Finaliza el comentarista destacando que la única consecuencia del vacío escrutado es la exclusión actual de prestaciones médicas del Convenio Multilateral Iberoamericano de Seguridad Social.

PALABRAS CLAVE: Ámbito material de aplicación, coordinación legislativa, prestaciones médicas.

\begin{abstract}
Annex III is totally empty, giving as a first impression that among the Iberoamerican States the international law of Social Security has sought only to agree on pecuniary benefits. However, a retrospective look accompanied by careful reflection may lead us to conjecture the inaccuracy of that panorama, and then to contemplate that this lack would have a practical explanation. The commentator ends by emphasizing that the only consequence of the emptiness sought is the current exclusion of medical benefits from the Multilateral Iberoamerican Agreement on Social Security.
\end{abstract}

KEYWORDS: Scope of material application, legislative coordination, medical benefits. 
SUMARIO

I. CONSIDERACIONES GENERALES

II. CONTEXTUALIZACIÓN DEL ANEXO III
A. ANTECEDENTES PERTINENTES
B. DIMENSIÓN SOCIOLÓGICA
C. DIMENSIÓN NORMATIVA VIGENTE
III. CONCLUSIONES

e-Revista Internacional de la Protección Social, ISNN 2445-3269. 2017, Vol. II, Nº1 


\section{CONSIDERACIONES GENERALES}

Nada de que lo siga puede suscitar interés auténtico si dejamos de lado que el alcance de la cobertura de la seguridad social se ha convertido en un tema central en buena parte de los países, no sólo de Iberoamérica, sino también de otras partes del mundo. Hay un marcado consenso en avanzar hacia la internacionalización de sus prestaciones, como se refleja en la estrategia de la Organización Internacional del Trabajo (OIT), a través de su Iniciativa Mundial de un Piso de Protección Social Universal.

De esa manera se entiende cabalmente que nuestro actual objeto de estudio, el Anexo III, se endereza hacia la consecución de que el Convenio sea el instrumento por excelencia para las soluciones mancomunadas frente a las diferentes contingencias vitales que excedan la preocupación monetaria de los beneficiarios. Lo esencial de la seguridad social es cubrir riesgos de subsistencia de diversa índole, debiendo extremarse el rigor de las operaciones jurídicas cuando puede llegarse al desconocimiento de derechos. Y, precisamente, este extremo pareciera acaecer al avizorar que el Anexo III figura despojado absolutamente de contenido.

Es que el Convenio Multilateral Iberoamericano de Seguridad Social (en adelante "el Convenio") se caracteriza como instrumento regional por enterrar el cimiento de su propio desarrollo ulterior, puesto que entre sus primeras normas se destaca que: "dos o más Estados Parte del presente Convenio podrán ampliar el ámbito objetivo del mismo, extendiéndolo a prestaciones o regímenes excluidos en principio. Los acuerdos bilaterales o multilaterales mediante los que se proceda a esa extensión y los efectos de la misma se inscribirán en el Anexo III" (art. 3.5). Entonces, el Anexo III no debería ser más que la materialización de esa preocupación por proyectar la movilidad ascendente de los beneficios del Convenio, inclusive con miras a avasallar su propio ámbito material congénito (prestaciones dinerarias).

Nosotros nos ocuparemos del asunto en relación a las prestaciones médicas que son medidas técnicas con las que la seguridad social iberoamericana lidia hace décadas en diversas latitudes, y no -por recorte metodológico- sobre la ampliación del Convenio a regímenes especiales (no contributivos, de asistencia social y víctimas de guerra).

\section{CONTEXTUALIZACIÓN DEL ANEXO III}

Como dejamos insinuado, la utilidad del anexo III se constata en el propósito de dar cabida a una progresiva cooperación regional en materias que originariamente el Convenio no alcanzó a comprender en el momento de su adopción por unanimidad, en la XVII Cumbre Iberoamericana de Jefes de Estado y de Gobierno, celebrada en Santiago de Chile (noviembre de 2007). Un ejemplo de expansión, promovido por este mismo tratado multilateral, serían las prestaciones médicas de la seguridad social (art. 3.1). Sin embargo, pese a la manifiesta buena voluntad de quienes concibieron esta posibilidad, luce manifiesto que ninguna convención se consigna todavía en el Anexo III, siquiera en tal aspecto puntual.

Al respecto, Sánchez-Rodas Navarro puntualiza que su redacción está inspirada en el Reglamento 883/04, aunque la normativa de la Unión Europea tiene un ámbito de aplicación material mucho más extenso: “...el Convenio Multilateral sólo se aplicará a las prestaciones de Seguridad Social de contenido económico, quedando excluidas las

e-Revista Internacional de la Protección Social, ISNN 2445-3269. 2017, Vol. II, No 1

http://dx.doi.org/10.12795/e-RIPS.2017.i01.18

Página 157 
prestaciones en especie". Todavía así, la profesora de Sevilla tiene presente que la Ley Orgánica 4/2000 sobre derechos y libertades de los extranjeros en España dispone en su art. 14.1 que "los extranjeros residentes tienen derecho a acceder a las prestaciones y servicios de la Seguridad Social en la misma condición que los españoles"1. García de Cortázar comparte que los recortes del campo material del Convenio, merced a su art. 3 , son la diferencia quizás esencial entre aquél y el Reglamento 883/04, sin que por esto dejen de ser textos equiparables y, sobre todo, coordinables ${ }^{2}$.

Justamente, una gran inquietud que persigue inclusive a los migrantes con radicación legal, en especial los temporales, es que las cotizaciones abonadas al régimen de seguridad social del país de origen se pierden porque los derechos a las prestaciones no son transferibles, siendo común que en el país de acogida haya un período de espera o "de carencia".

\section{A. ANTECEDENTES PERTINENTES}

El Convenio Multilateral se diferencia de su predecesor el "Convenio Iberoamericano de Seguridad Social” suscrito en Quito (1978). El último, previo a contemplar las prestaciones por vejez, invalidez y sobrevivientes, dedica el primer capítulo del Título II a las prestaciones "médico-sanitarias": "las personas protegidas de cada uno de los Estados Contratantes que presten servicios en el territorio de otro Estado Contratante, tendrán en el país receptor los mismos derechos y estarán sujetos a iguales obligaciones que los nacionales de este último Estado, en lo relativo a las prestaciones médicosanitarias que otorguen sus Sistemas de Seguridad Social, Previsión Social o Seguros Sociales" (artículo 6).

La literalidad nos llevaría a establecer que el Convenio de Quito no debería -a futuroser inocuo para el Anexo III, en tanto prevé un ámbito mayor de prestaciones entre varios Estados que suscribieron ambos. No obstante, su aplicación se supedita a un engorroso procedimiento, que en la práctica atomiza los esfuerzos: "Los Acuerdos Administrativos que se formalicen definirán el ámbito del presente Convenio en cuanto a las categorías de personas incluidas y exceptuadas, capítulo o capítulos del Título II que se dispone aplicar, fecha de vigencia y procedimientos de aplicación" (art. 17.b). Véase que en el vigente "Acuerdo Administrativo para la Aplicación del Convenio Iberoamericano de Seguridad Social de Quito entre la República Argentina y la República de Colombia" de 14 de abril de 2008, no figuran las prestaciones médicas en el ámbito de aplicación material (art. 2).

Por su parte, el "Acuerdo Multilateral de Seguridad Social del Mercado Común del Sur" también comprende las prestaciones de salud dentro del Título V pero, en lo sustancial,

\footnotetext{
${ }^{1}$ Sánchez-Rodas Navarro, C.; “Aproximación a la Coordinación de Regímenes de Seguridad Social en el Reglamento 883/2004 y en el Convenio Multilateral Iberoamericano de Seguridad Social”. e-Revista Internacional de la Protección Social, nº1/2016; p. 9.

${ }^{2}$ García de Cortázar, C.; "La Dimensión Externa de las Normas de Coordinación Europea de Seguridad Social. El Reglamento 883/04 y el Convenio multilateral Iberoamericano de Seguridad Social. Revista del Ministerio de Trabajo e Inmigración. Número extraordinario, 2010; p. 275.

${ }^{3}$ Asociación Internacional de la Seguridad Social; "Perspectivas de Política Social". Ginebra. AISS no 17/2011, s/n, https://www.issa.int/es_ES/resources/highlight.
}

e-Revista Internacional de la Protección Social, ISNN 2445-3269. 2017, Vol. II, Nº1

http://dx.doi.org/10.12795/e-RIPS.2017.i01.18

Página 158 
relega su aplicación a la legislación propia de cada Estado Parte (art. 3.2.), estableciendo expresamente que: “...serán otorgadas al trabajador trasladado temporalmente al territorio de otro Estado Parte así como a sus familiares y asimilados, siempre que la Entidad gestora del Estado de origen autorice su otorgamiento" (art. 6). Así, se extrae nuevamente la remisión a la legislación interna, además de la limitación proveniente del adverbio "temporalmente".

\section{B. DIMENSIÓN SOCIOLÓGICA}

Si se nos solicitara sugerir una tesis sobre la vacuidad misma, aventuraríamos que se explica por la manifiesta complejidad endógena frente a esta clase de prestaciones en especies. Para confirmar aunque no sea más que brevemente la hipótesis, tomemos a la República Argentina, por ser la última en depositar el instrumento de ratificación en la Secretaría General Iberoamericana y suscribir el Acuerdo de Aplicación (ambos actos consumados el reciente 31 de mayo de 2016) ${ }^{4}$.

En esa nación austral, las prestaciones médicas para la vejez son gestionadas por el Instituto Nacional de Servicios Sociales para Jubilados y Pensionados (conocido popularmente como "PAMI"), de conformidad a la ley 19032, el que se financia con el aporte del 3\% del haber de los trabajadores activos sujetos al régimen nacional general. Mientras tanto, las prestaciones médicas de los trabajadores activos son otorgadas por las obras sociales, comprendidas en la ley 23660 (Sistema Nacional del Seguro de Salud). Finalmente, las prestaciones médicas ante accidentes de trabajo, enfermedades profesionales y accidentes in itinere se rigen por la Ley de Riesgos del Trabajo, que las engloba dentro de las "prestaciones en especies" (ley 24557, art. 20). Esta última ley conforma un subsistema de la seguridad social, fuertemente privatizado por las Aseguradoras de Riesgos del Trabajo (ART).

Por otra parte, los países del "Cono Sur" registran un desempeño muy positivo -según la OIT- en cobertura formal por los regímenes de salud, mientras que otras subregiones de la misma Iberoamérica "...presentan un resultado menos favorable en sus niveles de cobertura, con una cuarta parte de la población sin cobertura por los sistemas de salud en la Región Andina, más de un tercio en América Central y hasta dos tercios en el Caribe"

Morales Ramírez establece en la faz histórica que la exclusión de la prestaciones médicas responde a las "...dificultades de coordinación entre las legislaciones de los países, en razón de las diferencias en la prestación del servicio y en la forma de retribuirlas" . Sin guardar elogios se ha adicionado: "el realismo de los redactores del CMISS es, en algunos supuestos, encomiable y digno de mención. En efecto, con gran elegancia y originalidad, resuelven la espinosísima problemática de las prestaciones

\footnotetext{
${ }^{4}$ http://www.oiss.org/Estado-de-Situacion.htm.

${ }^{5}$ IT, "La Estrategia de Desarrollo de los Sistemas de Seguridad Social de la OIT. El Papel de los Pisos de Protección Social en América Latina y el Caribe", Lima, OIT Oficina Regional para América Latina y el Caribe, 2014, p. 40, en http://www.ilo.org/americas/publicaciones/WCMS_317898/lang--es/index.htm.

${ }^{6}$ Morales Ramírez, M. A.; "Migración y Portabilidad de Derechos: el Convenio Multilateral Iberoamericano de Seguridad Social”. México, Instituto de Investigaciones Jurídicas de la UNAM. 2015; pp. 832 y 883 en: http://bibliohistorico.juridicas.unam.mx/libros/8/3984/36.pdf .
}

e-Revista Internacional de la Protección Social, ISNN 2445-3269. 2017, Vol. II, Nº1

http://dx.doi.org/10.12795/e-RIPS.2017.i01.18

Página 159 
sanitarias (prestaciones médicas) a través de la voluntariedad y la bilateralidad (...) debe reconocerse que las prestaciones medico/farmacéuticas son las que más problemas plantean de cara a su coordinación por lo que la opción elegida por el CMISS excluyendo "ex ante" estas prestaciones pero simultáneamente dejando "ex post" autonomía a los Estados para su inclusión bilateral, debe considerarse paradigmática"7.

En un todo de acuerdo, la Asociación Internacional de la Seguridad Social identifica las tres razones por las cuales los países del Sur con mayor emigración no intervienen más en negociaciones bilaterales o multilaterales de la seguridad social: magro desarrollo de las prestaciones de seguridad social nacionales, el bajo nivel de cobertura de la población local y la falta de recursos administrativos nacionales. Otra dificultad es la "falta de reciprocidad de ventajas", es decir, la falta de incentivos para que los países de acogida establezcan acuerdos bilaterales con las naciones de procedencia ${ }^{8}$.

Dicha descripción basta para convencer sobre los eslabones causales que llevan al atípico vaciamiento del Anexo III. En fin, a veces, “...en los procesos de integración se recurre a eliminación de ciertas normas, aunque pueda dar la impresión de constituir un retroceso, para lograr una aplicación más armónica y general del Convenio"”.

\section{DIMENSIÓN NORMATIVA}

Vimos que el Convenio Multilateral como legítimo sucesor del Convenio de Quito se arrogó el beneficio de inventario, pues excluyó de su haber hereditario a las prestaciones médicas. Sin embargo, aún hoy en día, podemos centrarnos más concretamente en los instrumentos bilaterales concebidos al reparo de ese primer tratado de internacionalización de la seguridad social. La cuestión a elucidar es cuáles pueden constituir terreno fértil para comenzar a trazar la senda hacia un nutrido Anexo III, adelantando que Uruguay es la república suramericana más ejemplar en el área.

Continuando tales coordenadas, hallamos que el Acuerdo Administrativo de Seguridad Social para la Aplicación del Convenio de Quito entre España y Panamá, con una extensa vigencia (desde 28/03/1980), regla que “...los beneficiarios de los Sistemas de Seguridad Social de España y Panamá, que residan o se encuentren en el territorio de la otra Parte Contratante, tendrán derecho a las prestaciones médico-sanitarias en los riesgos de enfermedad común y profesional, en accidente común y de trabajo y en maternidad, en los términos previstos en el presente Acuerdo" (art. 4), destacándose la referencia a "enfermedad común" y no sólo fruto de siniestros laborales.

En un grado inferior de eficacia normativa podemos encuadrar el Acuerdo Administrativo entre Portugal y Uruguay (vigente a partir de 01/12/1987), ya que atiende a las prestaciones de asistencia médico-sanitarias, pero la colaboración se sujeta a trámites formales como: presupuesto, aprobación de entidad gestora, facturación y

${ }^{7}$ OISS; "El Reglamento 883/04 y El Convenio Iberoamericano de Seguridad Social. Encuentros en el Camino"; p. 24, en: http://www.oiss.org/El-Reglamento-883-04-y-El-Convenio.html.

${ }^{8}$ AISS, ob. cit.

${ }^{9}$ Vidal Amaral, A. F. en: VV. AA.; Estudio sobre el Convenio Multilateral Iberoamericano de Seguridad Social. OISS. Madrid; 2012; p. 31 en: http://www.oiss.org/IMG/pdf/VII_Premio_OISS.pdf.

e-Revista Internacional de la Protección Social, ISNN 2445-3269. 2017, Vol. II, Nº1

http://dx.doi.org/10.12795/e-RIPS.2017.i01.18

Página 160 
reembolso (art. 8). Además, esa reciprocidad es objeto de reglamentación por las Partes (art. 9).

En último grado de protección, se verifica el Acuerdo Administrativo entre Uruguay y Venezuela (vigente desde el 24/09/1997), que llanamente legisla sobre un requisito del acceso efectivo a la prestación médica: "Para la adquisición, mantenimiento o recuperación del derecho a las prestaciones médico sanitarias, cuando un trabajador haya estado sujeto a la Legislación de ambas Partes Contratantes, los períodos de cotización cumplidos en virtud de la Legislación de cada una de ellas, podrán totalizarse siempre que no se superpongan" (art. 7). Pero sobresale la falta de cooperación en relación a la persona necesitada, pues tampoco se menciona la hipótesis de una "urgencia sanitaria", como sí lo hace el Acuerdo entre Portugal y Uruguay.

Ingresando a otro valioso tratado regional iberoamericano, puede divisarse que el Acuerdo Multilateral de Seguridad Social del Mercador Común del Sur (MERCOSUR) exhibe el Título III dedicado a "Disposiciones sobre las prestaciones de salud", que prevé la obtención de aquellas para los trabajadores, sus familiares o asimilados, durante el período de permanencia en el Estado Parte en que se encuentren (art. 4), mediando lisa y llanamente un certificado de la Entidad Gestora del Estado de Origen, en el que conste que el trabajador permanece sujeto a la legislación del Estado de origen (art. 3). Vale mencionar la plena operatividad de este Acuerdo desde el 1 de junio de 2005, a causa del Reglamento Administrativo, conforme a sus arts. 4 y 5.

\section{CONCLUSIONES}

Entrevemos que el Anexo III padece una carencia que solamente se justifica por la ausencia de instrumentos entre los Estados Parte que amplíen expresamente el Convenio en los términos literales de su art. 3.5. No obstante, no debe pensarse que en Iberoamérica no existe coordinación legislativa sobre prestaciones médicas.

Debe tenerse presente que del art. 8 del Convenio Multilateral se sigue que éste no deroga anteriores convenios internacionales, y hasta les otorga preeminencia si resultan más favorables para los migrantes, lo que ocurrirá siempre -por ahora- en lo atinente a prestaciones médicas, puesto que no forman parte del novísimo instrumento regional. $\mathrm{Si}$ a futuro, dos o más Estados encuentran que la cobertura de prestaciones médicas puede ser incluida, podrán utilizar como estructura al Convenio Multilateral, sea por acuerdo bilateral u otro multilateral, correspondiendo su comunicación a la Organización Iberoamericana de Seguridad Social.

A la fecha, existen sistemas de seguridad social de los Estados signatarios que se entrelazan legalmente para exceder la cobertura de prestaciones económicas. En efecto, siguen vigentes los tratados predecesores del Convenio Multilateral que contemplan manifiestamente a las prestaciones médicas, sobresaliendo tanto el Acuerdo del Mercosur como el Convenio de Quito, aunque el último limitado a sus consecuentes convenios bilaterales, inclusive, heterogéneos en relación a las prestaciones médicas: España-Panamá; Uruguay-Portugal; Uruguay-Venezuela.

En síntesis, frente al vacuo Anexo III, parece ineludible que los Estados Parte continúen las sendas ya trazadas por los instrumentos coordinadores señalados, integrando ese "páramo no tan desolado".

e-Revista Internacional de la Protección Social, ISNN 2445-3269. 2017, Vol. II, No 1

http://dx.doi.org/10.12795/e-RIPS.2017.i01.18

Página 161 